\title{
Análisis comparativo de la Leyenda La Llorona desde dos contextos diferentes
}

\author{
Nahúm Tórrez ${ }^{1}$ \\ Julián Montes ${ }^{2}$ \\ Víctor Montes ${ }^{3}$
}

\section{RESUMEN}

En este artículo, los autores realizamos un análisis comparativo de las versiones nicaragüense y colombiana de la leyenda La llorona, la cual es popularmente conocida en muchos contextos latinoamericanos. Nuestro análisis se fundamenta en un diseño de investigación cualitativo (Creswell, 2014), el cual se encarga de describir y analizar ideas, creencias, y prácticas de grupos, culturas y comunidades. Además, en el análisis narrativo de las leyendas nos apoyamos en ideas centrales sobre nivel de la historia y nivel del discurso, introducidas por el teórico búlgaro Tzvetan Todorov (1970) de corriente estructuralista en el análisis de relatos. Nuestros principales resultados revelan que hay varias similitudes y diferencias entre las dos versiones. Las dos historias tratan sobre una mujer que por decepciones de la vida arroja a su(s) hijo(s) a un río; es decir, ambas tienen un trágico final. Sin embargo, se identificaron diferencias significativas en cuanto a posibles moralejas de los relatos y los posibles receptores de los mismos. Al final, presentamos algunas consideraciones que pueden ser explotadas dentro del aula de clases en distintos niveles escolares.

Palabras claves: La llorona, relato, leyenda, análisis comparativo, estructuralismo.

Recibido: 18 de agosto de 2017

Aceptado: 27 de noviembre de 2017

1 Docente del Departamento de Educación y Humanidades, Universidad Nacional Autónoma de Nicaragua (UNAN-Managua/ FAREM-Estelí). Correo electrónico: ntorrez@unanfaremesteli.net

2 Egresado de la Maestría en Historia en la Universidad Tecnológica de Pereira, Colombia. Correo electrónico: conjuly@gmail. com

3 Egresado de la Maestría en Historia en la Universidad Tecnológica de Pereira, Colombia. Correo electrónico: victormontes2@ hotmail.com 


\title{
Analysis of the legend La Llorona from two different contexts
}

\begin{abstract}
In this article, the authors make a comparative analysis of the Nicaraguan and Colombian version of the legend La llorona (The Weeping Woman), which is popularly known in many Latin American contexts. Our analysis builds on a qualitative research design (Creswell, 2014), which aims to describe and analyze ideas, beliefs and practices of groups and communities. Moreover, for purposes of the narrative analysis we make, we use central ideas introduced by the Bulgarian scholar Tzvetan Todorov (1970), on story level and discourse level, following a structuralistic current of story analysis. Our main results reveal that there are several similarities and differences between the two versions. Both stories deal with a woman, who throws her babies into the river due to life disappointments; both women have a tragical ending. However, some significant differences were identified, mainly related to possible morals that can be taken from the stories and the possible receptors. At the end of the article we present considerations that can be exploited inside the classroom in different educational levels.
\end{abstract}

Keywords: La llorona, The weeping woman, story, legend, comparative analysis, structuralism. 


\section{INTRODUCCIÓN}

No hay ni ha habido jamás en parte alguna un pueblo sin relatos (Barthes, 1979, p. 9).

Un pueblo sin relatos es como una sopa sin sustancia (Silva, 1999, p. 11).

La visión del mundo y de los valores que tiene toda sociedad se expresan a través de sus historias, las cuales son transmitidas por medio de canales tales como la cultura popular y la literatura. Las historias que la gente escucha son de gran importancia para su interpretación del mundo y sus creencias del mismo (Salole, 2013, p. 76). Es por eso que, como dicen los dos pensamientos citados al inicio: "No hay ni ha habido jamás en parte alguna un pueblo sin relatos" (Barthes, 1979, p. 9), y "Un pueblo sin relatos es como una sopa sin sustancia" (Silva, 1999, p. 11).

La llorona es una leyenda conocida en muchas partes de América Central, América del Sur y en contextos hispanohablantes de los Estados Unidos (Tórrez \& Maagerø, 2016). La narrativa de la leyenda varía de contexto en contexto, siendo esta una característica principal de la tradición oral (Shepherd \& Humphries, 1994). Existe una diversidad de autores que sitúan sus orígenes en la creencia popular de México. Sin embargo, sea cual sea el origen, la mayoría de las narraciones de dicha historia, refieren a las apariciones de una mujer hermosa, vestida de blanco que irrumpe en las noches, tanto en entornos urbanos como semiurbanos, clamando por sus hijos desaparecidos. De la misma forma que esta mujer aparece misteriosamente, desaparece ante la sorpresa de quienes dicen atestiguar la leyenda (Rodríguez \& Verduzco, 2009).

Este trabajo nace a partir de una serie de conversaciones sostenidas en el mes de septiembre del año 2016, durante la Conferencia regional de IARTEM ${ }^{1} 2016$ en

1 International Association for Research on Textbooks and Educational Media (Asociación Internacional para la Investigación de Libros de Textos y Medios Educativos).
Pereira, Colombia, entre los autores de este artículo, el primero de nacionalidad nicaragüense y los dos siguientes de nacionalidad colombiana. Resultó interesante analizar y comparar la leyenda desde dos contextos diferentes. El presente artículo no es un estudio teórico del subgénero de las leyendas ni de la forma de su elaboración y de difusión; su objetivo principal está centrado en el análisis comparativo de dos versiones de La llorona, a partir de sus similitudes $\mathrm{y}$ diferencias.

El análisis se basa en conceptos centrales del modelo de análisis de relato, desde una perspectiva estructuralista presentado por el teórico Tzvetan Todorov (1970). La pregunta central que nos proponemos responder mediante este artículo es: ¿Qué similitudes y diferencias se encuentran entre la versión nicaragüense y la versión colombiana de la leyenda de La llorona? Antes de introducir los referentes teóricos en los que basamos nuestro análisis, presentaremos brevemente las dos versiones de la leyenda.

\section{Dos versiones de La llorona}

A continuación, presentamos brevemente la versión nicaragüense y colombiana de la leyenda de La llorona.

\section{La llorona - Versión nicaragüense $e^{2}$}

Trata sobre una joven indígena que vivía con su madre en un pueblo llamado Mogoyalpa, Ometepe. La joven solía ayudar a su madre en los quehaceres de la casa y en otras actividades como las demás jóvenes indígenas de la región. Un día, mientras ella lavaba ropa en el río, se acercó a ella un joven blanco, quien era de otro país. Después de ese día ellos empezaron a relacionarse hasta que ella quedó embarazada. Cuando ella le contó al joven de su estado, éste la abandonó pues no tenía la intención de llevársela a su país, ni hacerse cargo de la criatura que estaba por nacer. Al cabo de unos meses ella dio a luz. Al día siguiente,

2 Según Palma (1984). 
ella perdió el control pues recordó las palabras que su madre le dijo muchas veces: "La sangre del esclavo no debe mezclarse con la sangre del torturador”. Por esta razón, ella salió corriendo hacia el río con su bebé en sus brazos y al llegar lo aventó hacia el mismo. Al ver su hijo siendo arrastrado por las corrientes, ella intentó salvarlo, pero ya era demasiado tarde. Como resultado, ella perdió la razón y deambuló por el pueblo gritando “¡Ay, mi hijo!”, “¿Dónde está mi hijo?”, por lo que llegó a ser conocida como La llorona, de generación tras generación.

\section{La llorona - Versión colombiana ${ }^{3}$}

La llorona aparece en diferentes zonas del país y es el terror en diferentes zonas de Tolima, Huila, Antioquia y Cundinamarca. Aunque no hace daño, sus alaridos y gemidos son escalofriantes; su cuerpo es esquelético, al igual que su cara. Las razones de su lamento, se explica de muchas maneras. Unos dicen que era una joven de muy buena familia, pero que se enamoró de uno de los trabajadores de la finca de su padre; como la familia rechazaba esa relación, ellos decidieron fugarse, pero fueron descubiertos por los hombres de su padre, que mataron a su joven amante. Para entonces, la muchacha ya estaba esperando un hijo; por esa razón fue llevada de vuelta a la casa paterna, donde la encerraron. Poco después, dio a luz a un niño y, para que nadie se lo quitara la joven escapó con él en sus brazos, pero no se percató que el niño había nacido muerto. Por eso, la mujer llora su desgracia. Los campesinos dicen que La llorona se les aparece a los infieles y a los borrachos. Cuando un hombre sale a visitar a una mujer que no sea su esposa o su novia o cuando ha tomado mucho, se le aparece dando fuertes alaridos y lo espanta mientras lleva en sus brazos a su hijo muerto.

La fundamentación teórica se basa en el concepto y caracterización de la leyenda como subgénero narrativo, así como el modelo de análisis a seguir para la comparación entre la versión nicaragüense y colombiana de la leyenda de La llorona.

3 Según Silva (1999).

\section{La leyenda como subgénero narrativo}

La leyenda es un tipo de relato que pertenece al género literario épico, que además incluye la epopeya, la fábula, el cuento, el mito y la novela. En la actualidad este género recibe el nombre de narrativo. Además, se considera que la leyenda corresponde al género literario denominado folklórico o popular (Fournier, 2002). Para Valenzuela-Valdivieso (2011, p. 8),

La génesis de las leyendas es en la mayoría de los casos, la búsqueda de una explicación a través de un relato de un suceso o acontecimiento de forma no racional o científica. En otras ocasiones las leyendas narran sucesos -reales o irreales- sin comprobar; en consecuencia, para la ciencia y la historia como disciplina no son objeto de estudio en el recuento de acontecimientos de una sociedad en el tiempo y el espacio. En su estructura, es frecuente la combinación de elementos reales y falsos, pero en lo general, la leyenda no aborda un solo tema, sino varios a la vez, en yuxtaposición.

Las leyendas son narrativas culturales que generalmente se enfocan en una ubicación específica o en una figura histórica. De acuerdo a las investigadoras noruegas Mjør, Birkeland y Risa (2010), las leyendas fueron originalmente asociadas a textos no canonizados dentro de la iglesia católica; sin embargo, hoy en día este tipo de texto puede incluir relatos con una moraleja clara e incluso canciones. Las leyendas combinan milagros y contenidos fantásticos y usualmente tienen un contexto claro en tiempo y espacio.

\section{Análisis narrativo de relatos desde una perspectiva estructuralista}

Para Fournier (2005), la obra literaria se compone de contenido y forma, elementos que integran la estructura de una obra, llámese cuento, novela, teatro o poema. El argumenta que "la forma es el esqueleto o armazón en el cual se haya distribuido el contenido" (Fournier, 2005, p. 64). El análisis literario se basa en el estudio de los elementos constituyentes de un texto 
literario sobre la base de unos conocimientos teóricos para llegar a conocer cómo funcionan.

Nuestro modelo de análisis estará constituido por conceptos del estructuralismo, corriente teórica que se origina en el campo de la lingüística aplicada a la literatura en las primeras décadas del Siglo XX. Dicha corriente debe su sistema de análisis y métodos al Círculo de Praga, el cual es un grupo de teóricos rusos y se extiende hasta a los estructuralistas franceses. Según Aamotsbakken (2010), el estructuralismo ve la obra literaria como un sistema de estructuras que interactúan entre sí. Ella argumenta que cuando se analiza la relación entre el contenido y la forma de un texto, entonces se habla de 'estructura'.

Todorov (1970) sugiere que cualquier relato narrado posee dos niveles básicos: el nivel de la historia y el nivel del discurso. El nivel de la historia refiere al conjunto de los acontecimientos relatados o los hechos que constituyen la historia. Los elementos claves que se analizan en este nivel son: dónde, cuándo, quienes, cómo, etc., en el relato. Por otro lado, el nivel del discurso refiere a la forma en que se narra o presenta la historia. El análisis bajo este nivel incluye las técnicas narrativas y todos los recursos propios del arte de narrar. Al analizar un relato desde la perspectiva del discurso se pueden estudiar elementos como el narrador, discurso directo o indirecto, tiempo del discurso, figuras de retórica y de construcción, realismo versus idealismo, futurismo, realismo mágico y otros aspectos.

\section{MATERIALES Y MÉTODOS}

El análisis comparativo de las versiones nicaragüense y colombiana de La llorona se basa en un enfoque de investigación cualitativo. En este enfoque se exploran y se entienden los significados que los individuos o grupos atribuyen a un problema humano o social (Creswell, 2014). La investigación cualitativa pretende describir y analizar ideas, creencias, y prácticas de grupos, culturas y comunidades. El método de análisis de este tipo de investigación es interpretativo, contextual y etnográfico. Por tales razones, este diseño encaja con nuestros propósitos de investigación mencionados en parte introductoria de este artículo.

Como se mencionó en la Introducción, nuestro análisis comparativo de La llorona se fundamentará en conceptos centrales del teórico Todorov (1970), los cuales siguen una perspectiva estructuralista de análisis del relato. Considerando solamente algunas de sus ideas claves, limitaremos nuestro análisis en los siguientes elementos ${ }^{4}$ :

a. El marco del relato: el espacio y el tiempo en el cual se sitúa la acción

b. El discurso: la manera o forma en que se narra la historia

c. Los participantes: los personajes o sujetos presentes en los relatos

d. La secuencia narrativa: la historia narrada en sus tres momentos (inicio, nudo o clímax y desenlace)

e. El mensaje: las posibles moralejas del relato

Cabe destacar que ningún análisis literario es un análisis completo. Cada análisis estudia distintos elementos desde diferentes perspectivas. Por lo tanto, en nuestro estudio de La llorona nos enfocaremos solamente en los cinco elementos establecidos anteriormente. Empezaremos por analizar las versiones de la leyenda por separado, para luego comparar las dos versiones términos de sus similitudes y diferencias. Así mismo, complementaremos nuestro artículo con algunas breves reflexiones que pueden ser explotadas dentro del aula de clase en ambos países.

\section{RESULTADOS Y DISCUSIÓN}

\section{La llorona nicaragüense}

Según Palma (1984), la leyenda de La llorona ocurre en el pueblo llamado Moyogalpa, Ometepe, en Nicaragua.

4 Consideramos necesario establecer que el análisis se hará en forma de ensayo, es decir utilizando texto corrido, a pesar de listar los elementos que formarán la base de nuestro análisis de las leyendas. 
De modo que el contexto del lugar donde tienen lugar los eventos en el relato es presentado claramente. Sin embargo, no se ofrece información exacta del espacio de tiempo de la historia. Aun así, algunos investigadores asocian los eventos de la leyenda con el periodo colonial en la historia de Nicaragua (ver por ejemplo Tórrez, 2014). Aunque no se tiene certeza de este hecho, esta puede ser una posibilidad. Como se estableció anteriormente, las leyendas tienen generalmente un contexto claro de tiempo y espacio, como lo argumentan las investigadoras de texto Mjør, Birkeland y Risa (2010).

El discurso es narrado en principalmente tercera persona. Esto se puede ejemplificar tomando algunos segmentos del relato: "Ella salió corriendo hacia el río con su bebé en sus brazos y al llegar lo aventó hacia el mismo". Esta forma es utilizada para contar los eventos desarrollados por la joven indígena, así como los del joven extranjero, por ejemplo: “[...] éste la abandonó pues no tenía la intención de llevársela a su país, ni hacerse cargo de la criatura que estaba por nacer".

En el relato encontramos los siguientes personajes: La joven indígena (quien es la protagonista de la leyenda), la madre de la joven y el joven extranjero (el antagonista). Es interesante que a ninguno de los personajes se les asigne un nombre propio, o un sobrenombre. Este hecho crea cierta distancia con el receptor del relato, es decir el lector. En algunas narraciones de La llorona, como por ejemplo en el libro infantil ilustrado en el que se ilustra la versión mexicana, la joven es llamada 'María' (ver Hayes, Trego Hill \& Pennypacker, 2004). El asignar un nombre común a los personajes de un relato permite una mayor interacción entre el personaje representado y el receptor del texto; como en el caso de María, un nombre encontrado en todos los pueblos latinoamericanos, y en este caso nicaraguenses. En tal caso, el lector podría razonar, "esto me puede pasar a mí".

Tocante a la caracterización de los personajes por medio del lenguaje verbal, la joven es identificada como una persona diligente (ayuda a su madre en los quehaceres de la casa), inexperimentada (cae profundamente enamorada del joven extranjero) y un tanto desobediente (no obedece a su madre cuando ella le dice que "la sangre del torturador no debe mezclarse con la sangre indigena"). Su madre es representada por una persona interesada en su hija y firme, pues le advierte de los peligros que puede enfrentarse a su edad. En cuanto al joven, es representado como una persona extranjera y carente de amor por la joven y por el hijo, al que abandona antes de nacer.

La secuencia narrativa de leyenda se presenta de forma cronologica. El inicio del relato introduce a la protagonista del mismo, se presenta una caracterización de ella como se muestra en el párrafo anterior. En el nudo o climax se narran los eventos cruciales del relato: la joven encuentra al joven en el río, se enamora de él, tienen coito y queda embarazada. Luego ella le cuenta de su situación al joven, quien no tiene ninguna intención de hacerse responsable de sus actos y llevarse a la joven y a la criatura que esperan a su país. Finalmente, el desenlace describe las terribles consecuencias de las malas decisiones de la joven: ella pierde el control de sus emociones, lanza a su bebé al río, decide tratar de salvarlo cuando es demasiado tarde y, por esa razón, termina deambulando por las calles gritando: “Ay, mi hijo”, “¿Dónde está mi hijo?”

Por último, es interesante considerar las posibles interpretaciones de las enseñanzas o moralejas que se pueden extraer de la versión nicaraguense de La llorona. En el estudio de tesis realizado por Tórrez (2014), se crea un relato digital" intitulado "La Obediencia a tus padres asegura tu futuro". En dicho relato se destacan las trágicas consecuencias de las malas decisiones de la joven indigena, el relato concluye con la contundente oración: "No obedeció, y al fracaso llegó". Otra de las

5 Un relato digital consiste en la producción de videos cortos con recursos tecnológicos sencillos, en el cual el narrador cuenta su historia utilizando su propia voz. Las imágenes pueden ser propias o tomadas desde el Internet. La característica principal de un relato digital es el enfoque en la historia a narrar y no necesariamente en la tecnología empleada o el resulto final, el video corto (Haug, Jamissen \& Olhman, 2012). 
posibles moralejas del relato pueden relacionarse con la necesidad de conocer bien a una persona extranjera, antes de empezar una relación seria con esta. En el caso de la joven, que al final se convierte en La llorona, no se toma el tiempo suficiente para conocerlo, tiene amoríos con él y sufre las terribles consecuencias de sus actos. Como se mencionó anteriormente, ningún analisis de relatos es completo puesto que estos tienen mucho potencial de discusion de su contenido $\mathrm{y}$ posibles moralejas.

\section{La llorona colombiana}

En Colombia, aunque la mayoría de su población actualmente vive en zonas urbanas, esto no siempre ha sido así, el poblamiento de las grandes urbes ha sido paulatino y progresivo y se ha dado especialmente en el siglo XX. Debido a su extensión y su topografía montañosa, las regiones colombianas se encuentran fácilmente aisladas unas de otras, por lo que tal vez la leyenda de la llorona haya ido tomando matices distintos en cada lugar del país.

Aunque la leyenda parece ser un relato más propio de los pueblos boyacenses como se señaló anteriormente, La llorona es más fácilmente reconocida en el departamento del Valle del Cauca, región lejanamente distante de Boyacá pero que también es un reconocido centro económico del país. En este incluso existe un lugar llamado cerro La llorona. Además de esto, en el Sistema Nacional de Información Cultural (SINIC, $2015)^{6}$ aparece una corta reseña de La llorona sin ninguna referencia ni autor pero aparece referida al Valle del Cauca. De igual manera, en la página Web de la gobernación del Valle del Cauca, aparece el mismo contenido del SINIC sobre La llorona, aunque tampoco aparece su autor.

Respecto del momento en que aparece la leyenda de La llorona no hay alguna referencia exacta que permita definir algún marco temporal, sin embargo, al parecer

6 Sistema nacional de información cultural de Colombia (ver http://www. sinic.gov.co/SINIC/ColombiaCultural/) sus rastros se extienden hasta el establecimiento del dominio hispánico sobre el continente.

La 1lorona contiene elementos similares a otras leyendas, no solamente de la región latinoamericana sino también de la mitología europea y tal vez de otras regiones. Es posible que el origen de La llorona este en la mitología mexicana como se muestra por ejemplo en la versión de Stella Maris Rodríguez Tapia y Gabriel Ignacio Verduzco Argüelles. Siguiendo esta hipótesis, tal vez las versiones de meso y sur américa sean variaciones de una historia originada en México que ha sido transmitida y transformada paulatinamente por los pueblos que la han conocido fundamentalmente porque la manera de transmisión de la leyenda es la oralidad.

La leyenda no está relatada en tercera persona, sino de forma descriptiva combinando varios tiempos del verbo. Esta inicia detallando algunas características personales de los personajes para crear una imagen de terror y miedo. La leyenda dice que La llorona hace "gemidos escalofriantes, su cuerpo y su cara son esqueléticos, y se lamenta terriblemente"; acto seguido se cuenta quien era "una joven de muy buena familia... que desobedeció a sus padres al enamorarse de uno de los trabajadores de la finca". Producto de ello se embarazó y su enamorado fue asesinado, dio a luz a un niño muerto y entró en desgracia.

En el mismo orden antes descrito aparecen los personajes; una muchacha (el personaje principal sobre el que ejerce la fuerza del relato y a la que intuitivamente se le atribuye la culpa de desgracia), el segundo personaje es su enamorado un trabajador de la finca, propiedad de un tercer actor, su padre de quienes no se dice nada más que el papel que ejercieron en el relato. Un cuarto actor son los "hombres del padre de la finca" que ejercen la acción de matar al enamorado de la muchacha. El último lugar en la acción lo ocupan los campesinos que aseguran que La llorona se les aparece a "los infieles y borrachos". Llama la atención que en 
este relato la llorona espanta a hombres dando fuertes alaridos mientras lleva en brazos a su hijo muerto, a diferencia del relato nicaragüense donde lamenta a su hijo muerto diciendo "Ay mi hijo".

En este orden de ideas la leyenda hace énfasis en mostrar como una muy buena muchacha por involucrarse en una relación rechazada por la familia cae en la desdicha, no se caracteriza a los personajes más allá de decir su función en la leyenda. La muchacha era de muy buena familia, su padre tenía una finca y unos hombres lo que permite entender que era una joven de familia hacendada agravando más los hechos de su desgracia ya que por involucrarse en una relación rechazada no solo por su padre sino por su familia perdió todo, incluso se perdió así misma. La leyenda dice "por eso la mujer llora su desgracia" termino que se entiende como desdicha, adversidad, infortunio, desventura. La leyenda no dice que lora su perdida, o duelo, o sufrimiento con lo que se da a entender que la desobediencia lleva a la desgracia haciendo ver como peor el hecho de rebeldía. Tal vez con la leyenda no solo se advierte sobre los riesgos de la "infidelidad" sino más bien que se les dice a las jóvenes muchachas y madres por extensión sobre los riesgos de desobedecer a la familia representada por el padre y lo masculino. La leyenda habla de "la finca de su padre; los hombres de su padre; llevada de vuelta y encerrada en la casa paterna y finalmente el niño muerto" con lo que se observa una masculinización de la propiedad, del poder, de la fuerza y del control de la familia, hecho que no se debe desobedecer.

El hecho de que el resto de la leyenda está contada casi toda en masculino es significativo frente a la fuerte oleada de lecturas que hay alrededor de la Llorona en las últimas décadas del siglo XX desde la perspectiva de la reivindicación de la mujer frente al hombre. Este punto es claramente identificable por el lado de leyenda nicaragüense donde la referencia de obediencia y control la ejerce la madre y no el padre, caso contrario de la leyenda colombiana.
El inicio de La llorona en la versión colombiana relata la tétrica caracterización de la protagonista, confrontando su aspecto con la descripción del buen origen que tenía antes de su desgracia. Seguidamente se relatan en orden los eventos que la llevaron a tal situación haciendo énfasis en que a su estado llega por involucrase en una relación rechazada por la familia representada en todo el relato androcéntrica y patriarcalmente. Finalmente, el relato termina con la creación de un símbolo "el niño muerto" que será utilizado para recordar no solo la desgracia de la muchacha "sino" para moralizar sobre los actos de rebeldía hacia la fuente del orden y el poder en la familia. Así, desobedecer al padre lleva a la muerte del hijo y la desgracia de la madre.

De tal suerte que en la versión colombiana de la llorona no solo se construye un imaginario simbólico para prohibir a riesgo de coacción, terror y turbación la infidelidad, el desorden (borrachera) o la desobediencia explicitas en el relato, en definitiva, cualquier preferencia dionisiaca sin control ni freno propias de lo humano; sino además que la leyenda increpa, advierte y ata el modelo de clan familiar androcéntrico y patriarcal predominante en la mayoría de las regiones del país donde los "padres" escogían con quien casar a sus hijos e hijas a través de la puesta en escena de un relato en forma de leyenda que seguramente tuvo más de hecho que de mito. Ni el aspecto de la muchacha ya en desgracia es descrito tan fantasmagóricamente, ni los hechos acaecidos son tan descabellados. Es plausible que en muchas regiones del país hayan sucedido hechos similares. Tal vez las mencionadas "apariciones, alaridos y espantos de la llorona" no son más que los códigos que se crean en quien escucha la leyenda cuando cada vez que es contado nuevamente el relato. No es ni material ni positivamente real tal aparición, pero el relato y su mensaje se suman al imaginario normativo y moralizador que se construye a través de este tipo de leyendas, sobre todo si son contadas en contextos familiares y desde personajes cronológicamente desiguales (de padres o personas 
mayores a hijos, allegados o conocidos) lo que constituye marcos referenciales de comportamiento.

\section{Similitudes entre las dos versiones}

Una de las principales similitudes de la versión nicaragüense y la versión colombiana de La llorona es su trágico final, pues en las dos la protagonista se convierte en una persona fuera de la realidad, que o deambula por las calles gritando "¡Ay mis hijos!”, o se le aparece a infieles y borrachos, dando fuertes alaridos y espantándolos. En ambas versiones aparece otro personaje que representa un modelo de familia, en la nicaragüense es la "madre" y en la colombiana es el "padre", dando con ello a entender el aspecto familiar para el que se cuenta la historia sobre todo si se tiene presente que fue la desobediencia en ambos casos lo que produjo o la perdida de razón o la desgracia. También el hecho de que en ambas versiones el embarazo sea tan explícito deja entrever que la leyenda buscaba que se tuviera presente que si una muchacha se relacionaba con hombres se podía embarazar, que la finalidad del enamoramiento era tal vez formar otra familia y que por consiguiente había riesgos que no se podían correr al respecto.

Cuando se lee o escucha una historia, es común esperar un final feliz, en la mayoría de los casos se espera que los protagonistas superen los peligros y terminen felices con sus seres queridos. Sin embargo, "esta no es una regla absoluta en tiempos modernos y algunos rompen ese patrón" (Maagerø, 2012, p. 194, nuestra traducción). Las historias que no tienen un final feliz tienen mucho poder en transmitir su mensaje, puesto que dejan claro que el trágico final es producto de los eventos en el desarrollo, muchas veces siendo el caso de malas decisiones. Este es el caso de La llorona en las dos versiones analizadas.

\section{Diferencias entre las dos versiones}

Una de las diferencias en las dos versiones elegidas para análisis es el orden o secuencia narrativa con la que se ofrece lo narrado. Según Barthes (1977), no siempre la historia se ofrecerá al lector en forma cronológica, mientras en la versión nicaragüense la advertencia de la desobediencia aparece mucho después de ocurridos los hechos en la versión colombiana desde el principio se deja claro que la relación de la joven era rechazada por la familia. Mientras en la primera versión la joven trata de enmendar su error lanzando al bebe al rio, en la segunda la muchacha quiso que nadie le quitara a su hijo. De tal manera que las dos versiones son dirigidas a receptores distintos. La nicaragüense está dirigida a niños y jóvenes desobedientes que si salen a la calle se los puede llevar La llorona (ver Muños, 2008), en la versión colombiana La llorona no hace daño y solo busca espantar tenebrosamente a borrachos y hombres infieles (Silva, 1999).

\section{CONCLUSIONES}

La leyenda es un recurso que fortalece la identidad de toda sociedad, esta tiene un valor histórico debido por su contenido (sucesos que se narran) y por su antigüedad. Además, tiene un valor etnográfico, cuando a través de la narración se identifican costumbres o formas de vida de una población específica (Valenzuela-Valdivieso, 2011, p. 9). Según Silva (1999, p. 11), “el universo mítico y legendario se configura en parte sustancial del patrimonio cultural de toda nación. En muchos casos estos relatos dieron origen a la literatura, a la ciencia, a la cultura, y son mucho más que formas del folclor local".

El análisis de la versión nicaragüense y colombiana de La llorona revela varias similitudes y diferencias, que aunque influenciadas tal vez por razones geográficas o políticas, se distinguen más por los objetivos que se persiguen con la leyenda. Si bien las dos historias tratan sobre una mujer que pierde la razón (la embaraza un extranjero y ella lanza a su bebe a un rio) o entra en desgracia (le matan a su amante y da a luz un hijo muerto), los mensajes de las leyendas no son muy distintos: la desobediencia a la familia conlleva a decepción y desgracia, tal vez no en vano en los 
contextos latinoamericanos un embarazo sea visto como un impedimento y un entorpecimiento de los proyectos personales cuando se da por fuera del matrimonio o cuando el hombre' no se hace cargo del hijo o hija. El embarazo de adolescentes como problema social en contextos latinoamericanos tiene mucho potencial para ser discutido en escuelas primarias y secundarias, y la leyenda de La llorona puede ser un buen punto de partida en tal discusión (ver Maagerø \& Zelaya, 2012; Tórrez \& Maagerø, 2016).

\section{BIBLIOGRAFÍA}

Aamotsbakken, B. (2010). Strukturalisme og tekstlingvistikk.IS. V.Knudsen \& B. Aamotsbakken (red.): Teoretiske tilncerminger til pedagogiske tekster. Kristiansand: Høyskoleforlaget

Arellano, J. E. (1997). Literatura nicaraguense. Managua: Hispamer

Barthes, R. (1999). Mythologies. Paris: Editions of Seuil

Barthes, R. (1970). Introducción al análisis estructural de los relatos. En Barthes, R., Greimas, A. J., Bremond, C., Morin, V., Metz, C., Todorov, T. \& Genette, G.: Análisis estructural del relato. Buenos Aires: Editorial tiempo Contemporáneo (Traducción directa del francés: Beatriz Dorriots)

Creswell, J. W. (2014). Research design qualitative, quantitative, and mixed methods approaches (4th Ed.). Thousand Oaks, CA: SAGE Publications

Fournier, C. (2002). Análisis literario. Madrid: Cengage Learning

Fournier, C. (2002). Análisis literario. Ciudad de México: Thomson

Franklin, K., \& Herrera, M. (2000). Historia del istmo centroamericano (Tomo I). San José: Coordinación Educativa y Cultural de Centro América

Hayes, J., V. Trego Hill \& Pennypacker, M. (2004). La Llorona. The Weeping Woman. El Paso, Texas: Cinco Puntos Press
Haug, K., Jamissen, G., \& Ohlmann, C. (2012). Digitalt fortalte historier. Refleksjon for læring Oslo: Cappelen Damm Akademisk

Mjør, I., Birkeland, T. \& Risa, G. (2000). Barnelitteratur - sjangrar og teksttypar. Oslo: LNU/Cappelen

Maagerø, E. (2012). Heltefortellinger og andre fortellinger med lykkelig slutt. I Bjorvand, A., \& Tønnessen, E. (red): Den andre leseopplceringa. Utvikling av lesekompetanse hos barn og unde. (2. utgave). Oslo: Universitetsforlaget

Maagerø, E. \& I. Zelaya (2012). Veggmaleri som multimodal tekst. I: T. Hestbæk Andersen \& M. Boeriis(red.).Nordisksocialsemiotik.Pcedagogiske, multimodaleog sprogvidenskabelige landvindinger. Odense: Syddansk Universitetsforlag

Palma, M. (1984). Por los senderos míticos de Nicaragua. Managua: Nueva Nicaragua/Monimbó Rodríguez, S. \& Verduzco, G. (2009). La Llorona: Análisis literario-simbólico. En Teresa López

Pellisa y Fernando Ángel Moreno Serrano (eds.): Ensayos sobrecienciaficcióny literaturafantástica: actas del Primer Congreso Internacional de literatura fantástica y ciencia ficción (1, 2008, Madrid). Madrid: Asociación Cultural Xatafi: Universidad Carlos III de Madrid, 2009, p. 306318

Salole, L. (2013). Krysskulturelle barn og unge. Om tilhørighet, anerkjennelse, dilemmaer og ressurser. Oslo: Gyldendal akademisk

Shepherd, S., \& Humphries, T. (1994). Myths and legends from around the world. London: Marshall Editions Development LTD

Silva, F. (2009). Mitos y leyendas colombianos. Bogotá: Panamericana Editorial

Sistema Nacional de Información Cultural SINIC (2015). Mitos y Leyendas. Valle del Cauca. Ministerio de Cultura de Colombia. https://goo.gl/ mQJMt4

Tórrez, N. \& Maagerø, E. (2016). Den latinamerikanske legenden om La Llorona (Den gråtende kvinnen) i bildebok og i barnehage/skole. I Norunn A. \& Bente A. (2016). Folk uten land? $\AA$ gi stemme og status 
til urfolk og nasjonale minoriteter. Kristiansand: Portal Akademisk

Tórrez, N. (2014). Transforming Nicaraguan myths into digital stories: The potential of Digital Storytelling as a pedagogical text in a Nicaraguan context. Master's thesis at Høgskolen i Buskerud \& Vestfold, Norway
Valenzuela-Valdivieso, E. (2011). La leyenda: un recurso para el estudio y la enseñanza de la Geografía. Investigación Universitaria Multidisciplinaria - año 10, $n^{\circ}$ 10, diciembre 2011 